\title{
AQUATIC INVERTEBRATES
}

\section{A NEW TADPOLE SHRIMP, Triops longicaudatus, IN SASKATCHEWAN}

\section{HENRY MANN, Sir Wilfred Grenfell College, Corner Brook, NL A2H 6P9}

Email: hmann@swgc.mun.ca and M.V. S. RAJU, Suite 307, 477 Superior St., Victoria, BC V8V 1 T5

While investigating plants and animals in the field, invariably unexpected observations will be made, sometimes related and sometimes unrelated to the original purpose. It is this fundamental feature of field biology that makes it an appealing and exciting pursuit for naturalists and scientists alike. Such was the case in the summer of 2000 while searching for charophytes, aquatic plants also known as "stoneworts", in ephemeral aquatic habitats of the Regina area. Stoneworts are complex large green algae with stems and branches that superficially mimic the structure of vascular plants. The rare Macoun's Nitella (Nitella macounii) as well as other stoneworts occur in these habitats. ${ }^{5}$

On July 19, 2000 we examined an inundated depression in a grain field on the south side of the Trans-Canada Highway about $0.6 \mathrm{~km}$ west of the Pinkie Road junction (Figure 1). Wading in the clear shallow water of such pools we could easily spot the bright green growth of charophytes which we collected by hand. This particular pool was only $30 \mathrm{~cm}$ deep and appeared ideal for the growth of stonewort species adapted to ephemeral habitats, however, a careful survey of the entire water body turned up only one tiny, somewhat stunted plant of Braun's Stonewort (Chara braunii). The substrate seemed to be different from other flooded depressions we had investigated, having a fibrous crusty covering which had obviously been dry before the pool was again inundated by summer thunderstorms.

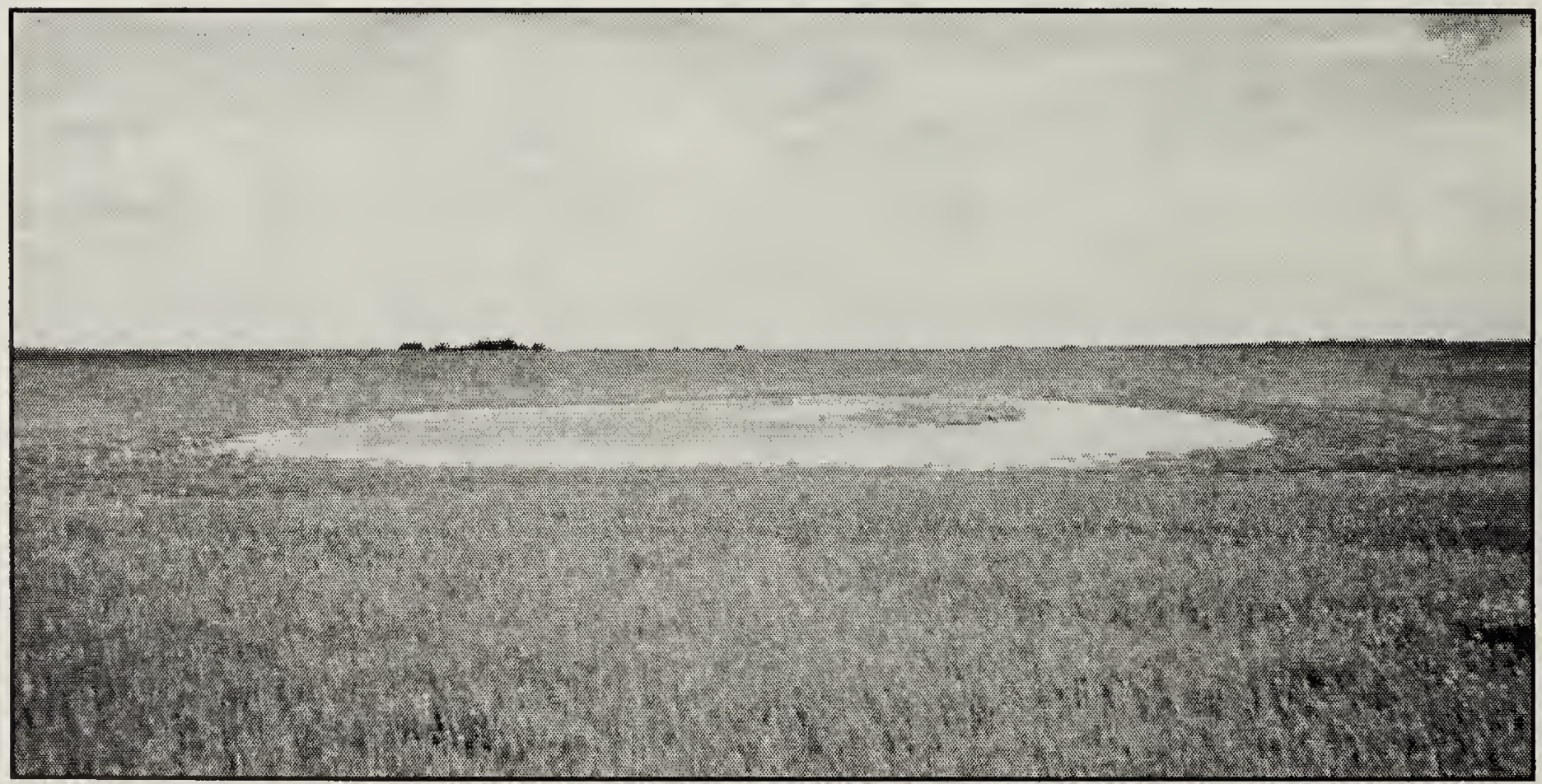

Figure 1. Ephemeral grainfield pool with tadpole shrimp Triops, facing south from Trans-Canada Highway.

Henry Mann 


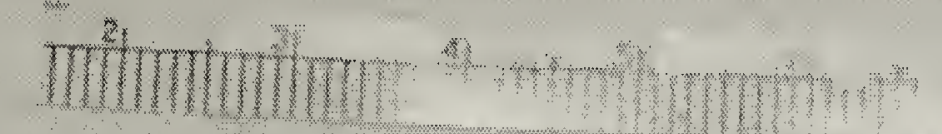

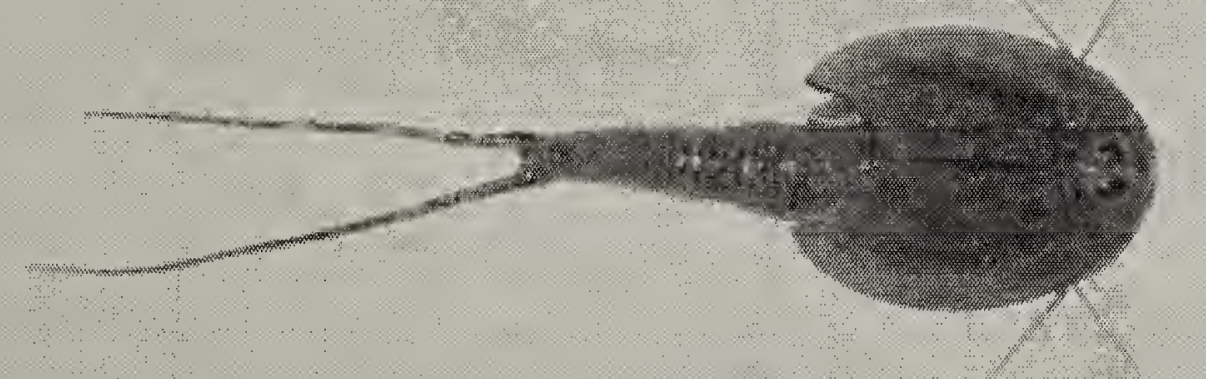

Figure 2. Dorsal view of tadpole slirimp, Triops longicaudatus.

Henry Mann

Most surprising were the large, strangelooking animals that seemed to appear from nowhere and then quickly dart off, hiding themselves in the loosely flocculent substrate. They appeared to be very numerous. We had not seen anything like this before in the many dozens of shallow depressions previously investigated in this and previous years. Although difficult without proper equipment, we managed to capture one of the creatures which neither of us could recognize. It looked like a miniature marine horseshoe crab with a long jointed tail, almost prehistoric in appearance. So, along with the day's collection of stoneworts, our mysterious little beastie was whisked off to the laboratory for further examination.

Without too much difficulty we were able to determine the group to which the animal belonged: the tadpole shrimp, Crustaceans of the Order Notostraca. Identification to species would have to wait until the appropriate literature was acquired, but in the meantime we examined our unusual creature under the stereoscope. The crustacean was $6.5 \mathrm{~cm}$ long from its rounded head-thorax end to the tip of the two long tail spines (Figure 2). The anterior shell (carapace) was $1.8 \mathrm{~cm}$ wide and greyishbrown in color with two dark brown eyespots near the front. Projecting from either side of the carapace were thin hair-like "feelers" (first thoracic appendages). On the underside could be seen many overlapping segments with gills which beat in rhythmic fashion. Its long tail-like abdomen was quite flexible, composed of jointed plates. The end segment, known as the telson, bore two long spines (caudal rami). At certain lighting angles, surfaces of the carapace and abdomen plates produced a slight iridescence. Figure 3 illustrates some of the gross structural features of the organism. Further perusal of the literature determined our specimen to be Triops longicaudatus. ${ }^{4}$

Four members of the Notostraca are known from Canada, one in the genus Triops and three in the genus Lepidurus, as indicated in Table 1. ${ }^{1}$ T. longicaudatus, the only Triops in North America, ranges from Mexico to southern Canada, but only inhabits the drier western portion of the continent where desert and semi-desert conditions prevail. It can easily be distinguished from members of the genus Lepidurus all of which have a supra-anal plate on the last tail segment (the telson). ${ }^{2}$ Triops does not (Figure 3 ). It appears that this report at the northern edge of its range is the first record for Saskatchewan. A preserved specimen is housed in the herbarium of the Sir Wilfred Grenfell College, Corner Brook, NL.

Few organisms utilize temporary pools, which dry out most summers, as their primary habitat. The major feature of tadpole 


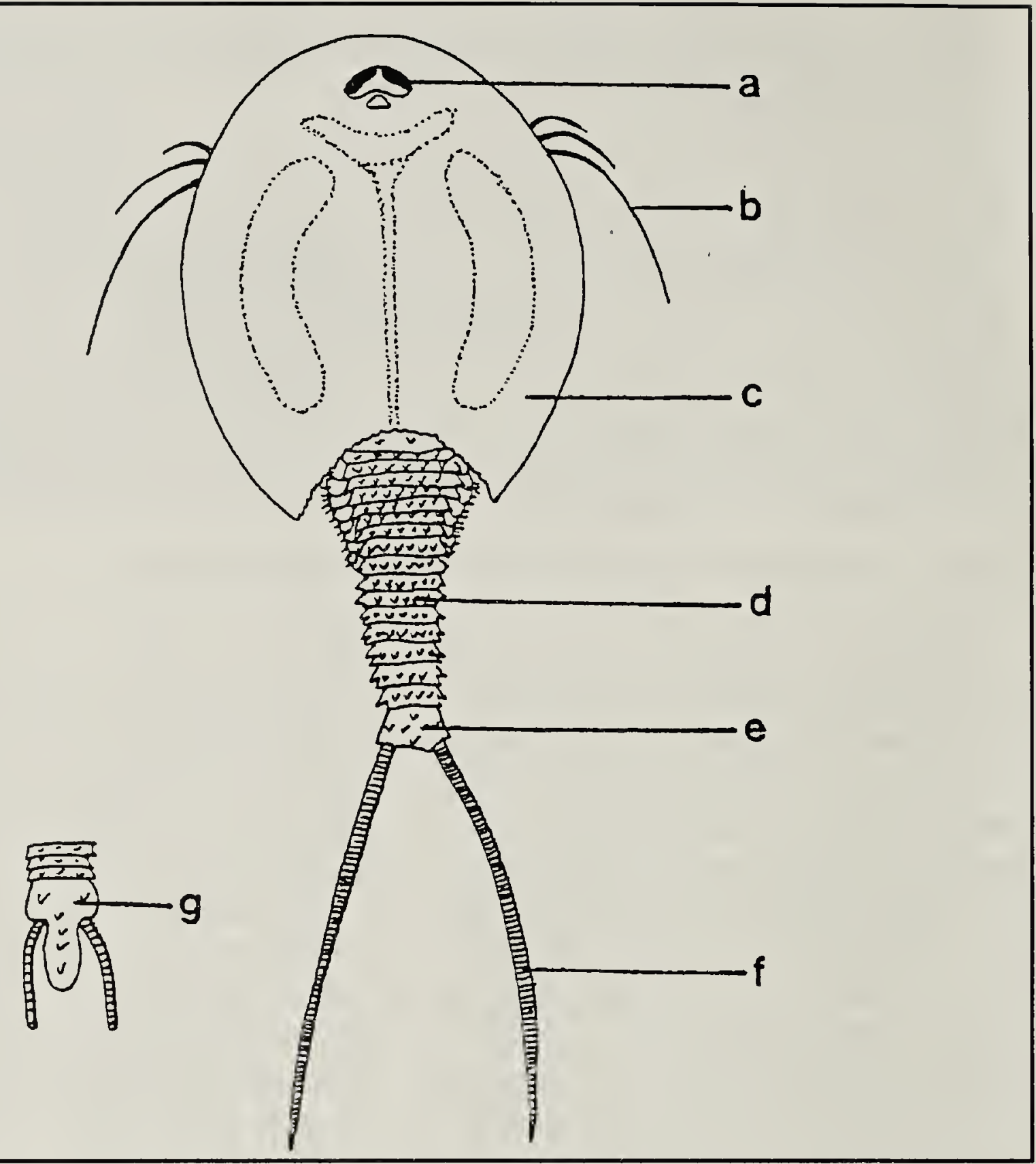

Figure 3. Dorsal diagram of Triops and its distinction from the genus Lepidurus. a. eye. b. first thoracic ("feeler") appendage. c. carapace of head and thorax. d. abdomen segment. e. telson. f. posterior spine (caudal ramus). g. telson of Lepidurus species with projecting supra-anal plate.

Henry Mann

shrimp which makes this possible is their drought-resistant eggs. Under ideal conditions dried eggs can remain viable for decades. Eggs are also the only means of dispersal. The crusty, almost paperyflocculent surface substrate of dried pools can readily be dispersed by high winds, especially whirlwinds (dust devils) so common in the dry west. Eggs are sticky when laid and easily adhere to waterfowl and shore birds. There is some suggestion that they may even be able to pass through the intestines of birds and still retain their viability. ${ }^{3}$ A necessary adaptation to life in ephemeral ponds is a rapid life cycle, reported to be a mere 20-40 days in this species. The short life cycle and droughtresistant eggs have made tadpole shrimp very popular for laboratory culture, student projects, as aquarium pets, and their use as live fish food. Eggs can be purchased from biological supply houses or from various vendors on the Internet along with culture instructions. Regina residents now have a ready source simply by collecting a bit of substrate from this particular pool. Websites for information on Triops and Lepidurus species abound on the Internet, literally in the thousands!

While informing ourselves about the curious little creature, we quickly came to 
Table 1. Species of tadpole shrimp known from Canada. ${ }^{1}$

\begin{tabular}{|l|l|}
\hline \multicolumn{1}{|c|}{ Province/Region } & \multicolumn{1}{c|}{ Species } \\
\hline Alberta & $\begin{array}{l}\text { Lepidurus conesii } \\
\text { Lepidurus lynchi } \\
\text { Triops longicaudatus }\end{array}$ \\
\hline Saskatchewan & $\begin{array}{l}\text { Lepidurus collesii } \\
\text { Lepidurus lynchi } \\
\text { Triops longicaudatus* }\end{array}$ \\
\hline Manitoba & Lepidurus couesii \\
\hline Arctic Canada & Lepidurus arcticus \\
\hline
\end{tabular}

*current report

realize that stoneworts and tadpole shrimp have much in common. An aquatic plant and an animal have adapted in parallel ways to the same type of ephemeral habitat where few other species are present as competitors or predators. Tadpole shrimp have developed drought-resistant eggs passively dispersed by wind or on the bodies of waterfowl. Stoneworts have developed drought-resistant spores which can remain viable for decades in the dried state and which are dispersed in and on waterfowl, and in blown dust. Eggs and spores exhibit variable dormancy, not all germinating at the same time, some remaining viable and inactive for many seasons to ensure long-term survival in unpredictable temporary habitats. Both have rapid growth and short life cycles, and both are food sources for waterfowl thereby insuring contact with one of their major dispersal mechanisms. Both belong to groups going back hundreds of millions of years to the early beginnings of terrestrial life on this planet so they obviously have been enduringly successful despite the tenuous habitats they occupy.

We also suspect that there is a direct interaction between the two organisms which could be investigated in the future. Charophytes of temporary habitats tend to be small tender species and Triops is known to be a feeder on tender vegetation as well as on detritus and small invertebrates. This may well be the reason why this pool was almost totally devoid of stoneworts when they were present in other similar such pools without Triops. It has been shown elsewhere that certain stonewort species will be absent in water bodies that harbour high numbers of invertebrate herbivores such as amphipods. ${ }^{6}$ Perhaps tadpole shrimp also modify the substrate with their papery/crusty egg masses which possibly may inhibit stonewort germination and growth.

Despite their low biodiversity, ephemeral pools provide unique habitats for species often not found elsewhere. These species have developed various adaptations to cope with variable, unpredictable and extreme conditions imposed upon them. The ecology of these waters and the species that inhabit them deserve a much closer look.

1. HARTLAND-ROWE, R. 1965. The Anostraca and Notostraca of Canada with some new distribution records. The Canadian Field - Naturalist 79:185-189.

2. LAWRENCE, J.R. 1975. Tadpole shrimps in Beaver Creek, Saskatchewan. Blıe Jay 33(3):149-152

3. LONGHURST, A.R. 1955. Evolution in the Notostraca. Evolution 9: 84-86.

4. LONGHURST, A.R. 1955. A review of the Notostraca. Bulletin of the British Museum (Zoologv) 3(1): 1 - 57 .

5. MANN, H. and M.V.S. RAJU. 2002. First report of the rare charophyte Nitella macounii (T.F. Allen) T.F. Allen in Saskatchewan and western Canada. The Canadian Field-Naturalist 116(4): 559-570.

6. PROCTOR, V.W. 1999. Charophytivory, Playas y Papalotes, a local paradigm of global relevance. Austratian Joumal of Botany 47: 399-406. 